\title{
Domain-Specific Knowledge and Memory Performance: A Comparison of High- and Low-Aptitude Children
}

\author{
Wolfgang Schneider, Joachim Körkel, and Franz E. Weinert \\ Max Planck Institute for Psychological Research, Munich, Federal Republic of Germany
}

\begin{abstract}
Two studies compared memory performance and text comprehension of groups that were equivalent on domain-specific knowledge but differed in overall aptitude, to investigate whether prior knowledge about a particular domain or overall aptitude level was more important when the task was to acquire and use new information in the domain of interest. Both studies dealt with third-, fifth-, and seventh-grade soccer experts' and novices' memory and comprehension of a story dealing with a soccer game. Several measures of memory performance, memory monitoring, and text comprehension were used. Levels of soccer knowledge and of overall aptitude were varied in a factorial design. Neither study detected significant differences between high-aptitude and low-aptitude experts, regardless of their ages. Low aptitude experts outperformed high-aptitude novices on all memory and comprehension measures. The results indicate that domain-specific knowledge can compensate for low overall aptitude on domain-related cognitive tasks.
\end{abstract}

Since the late 1970 s, a growing body of research has examined the effects of domain-specific knowledge on memory strategies and performance on various memory tasks. These studies showed that children's prior knowledge substantially affects their choice of memory strategies and significantly influences memory performance (see Bjorklund, 1985; Chi \& Ceci, 1987; Ornstein \& Naus, 1985; Rabinowitz \& Chi, 1987; Schneider \& Pressley, 1989, for reviews). Undoubtedly, the most impressive evidence stems from studies contrasting the performance of experts and novices in a specific domain. Examples include studies of baseball expertise (Chiesi, Spilich, \& Voss, 1979; Spilich, Vesonder, Chiesi, \& Voss, 1979), studies of problem-solving in physics (e.g., Chi, Glaser, \& Rees, 1982), and studies comparing chess experts' and novices' strategies and moves (Chase \& Simon, 1973; Chi, 1978).

In one of the few developmental studies using the expertnovice paradigm, Chi (1978) was even able to demonstrate that child experts outperformed adult novices when the task was to memorize chess positions. From this study, it can be concluded that differences in domain-specific knowledge may outweigh all other memory differences between children and adults and can lead to impressive reversals of age-related improvements in cognitive performance. The superiority of the experts' performance was attributed to the impact of their rich domain-specific knowledge, which enabled them to recognize many domain-relevant patterns automatically and to solve domain-specific problems.

Given the powerful effects of domain-specific knowledge, a related question of interest-and the one of particular interest

This research was partially supported by Grant AZ II 36193 from the Volkswagen Foundation to Franz E. Weinert. We would like to thank Merry Bullock, Beth Kurtz, and Mitch Rabinowitz for their helpful comments on earlier versions of this article.

Correspondence concerning this article should be addressed to Wolfgang Schneider, Max Planck Institute for Psychological Research, Leopoldstrasse 24, D-8000 München 40, Federal Republic of Germany. in this study-is whether rich knowledge in a specific domain can compensate for low overall aptitude. Findings derived from the expert-novice paradigm suggest that individual differences in general reasoning skills as assessed in traditional psychometric intelligence tests do not prove important in distinguishing expert and novice performance. According to more recent conceptualizations of intelligence, high-aptitude individuals possess factual knowledge in many domains, whereas low-aptitude individuals lack experience in all but a few domains (cf. Gagné, 1985; Garcia, 1981; Siegler \& Richards, 1982). As psychometric intelligence tests typically sample knowledge from a wide variety of domains, the finding that low-ability individuals usually process information less effectively and efficiently than high-ability subjects may be due to the fact that their information processing abilities are assessed in domains with which they are not familiar. Hence, tests assessing psychometric intelligence or general aptitude may underestimate low-aptitude individuals' comprehension, memorizing, or decision-making skills in the few domains with which they are highly familiar. If this assumption is correct, individual differences in global reasoning skills should not prove important when the task is to acquire and process new information within a domain about which all subjects already know a lot.

Most studies using the expert-novice paradigm could not address this issue because they typically compared experts and novices whose overall aptitude was high (e.g., college students, university professors). The few empirical studies tapping this problem have yielded conflicting evidence. Bransford, Stein, Shelton, and Owings (1981) compared the performances of high- and low-aptitude fifth graders who were asked to learn a passage about robots. The high-aptitude children were clearly superior in activating preexisting knowledge to draw inferences and in asking themselves relevant questions about the information they were trying to learn. The low-aptitude students had the potential to do so, but did not do this spontaneously. On the other hand, Marr and Gormley (1982) analyzed the relationship between compre- 
hension ability and prior knowledge in fourth graders' recall of structurally equivalent texts and found no effects of ability. Instead, prior knowledge turned out to be the only powerful predictor of memory and comprehension performance.

With regard to our question of interest, one problem with interpreting the finding of the two studies was that children's domain-specific knowledge was not particularly rich in either study. Undoubtedly, the comparison of high- and low-ability experts in a given domain gives more important information concerning our central issue. Thus, we decided to reanalyze some of our data that were suited to deal with the problem. These data stem from two studies conducted within a largescale research project (Körkel, 1987; Weinert et al., 1984). In both studies, the expert-novice paradigm was used to assess the impact of domain-specific knowledge on text comprehension and recall. The two studies were comparable in that they investigated the influence of knowledge about soccer on comprehension and recall of a story about a soccer game, and in that third, fifth, and seventh graders served as subjects. At each age level, approximately half of the subjects were classified as soccer experts and half as novices according to their performance on a questionnaire that tapped knowledge of soccer rules and important soccer events. The two studies differed, however, with regard to the dependent variables used. Whereas memory for text details, the ability to draw inferences, and the ability to detect contradictions in the text were the major outcome measures in the first study (Weinert et al., 1984), various additional measures of memory, strategy use, and metamemory were available in the second study (Körkel, 1987). As several indicators of intellectual ability (i.e., psychometric intelligence tests) were available in both studies, it was possible to further subdivide the samples of soccer experts and novices into subgroups of high- and low-aptitude children.

\section{Experiment 1}

\section{Method}

Subjects. A total of 576 middle-class children (106 third graders, 236 fifth graders, and 234 seventh graders from rural and urban schools in the Heidelberg area) participated in the study. Equal numbers of boys and girls were included at each age level. All testing was done in group sessions.

Measures and procedure. A 13-item questionnaire was used to assess children's knowledge about soccer. Ten multiple-choice items tapped subjects' knowledge about soccer rules, whereas the remaining three items assessed knowledge about important soccer events. Each item on the questionnaire was given a score of 1 or 0 . (The maximum score was 13.) Children with scores ranging between 8 and 13 were classified as soccer experts, and those with scores below 8 were considered soccer novices. To identify high- and low-aptitude subjects within the groups of soccer experts and novices, children's scores on the verbal aptitude component of a German cognitive ability test (Heller, Gädicke, \& Weinläder, 1985) were considered. The three subtests used (i.e., vocabulary, sentence completion, and word classifications) assessed children's verbal comprehension as well as verbal reasoning skills. Mean scores obtained for our sample did not significantly differ from those reported by Heller et al. (1985), regardless of age and type of task under consideration.
At each grade level, those subjects scoring above the median of the distribution were classified as low-aptitude children. As a consequence, four groups were differentiated at each grade level: highaptitude soccer experts, low-aptitude soccer experts, high-aptitude soccer novices, and low-aptitude soccer novices.

All subjects were presented with a narrative text dealing with a soccer game. The story was about a young soccer player's experiences in an important match. After a short description of the young hero and his activities before the game, the course of action during the game was described in detail. The story ended with a description of the hero's physical and psychological condition after the game was over.

Precautions were taken to ensure that most parts of the story were easily understandable for novices. Amstad's (1978) version of the Flesch formula was used to assess text readability. This formula yields values ranging from low readability (0) to high readability (100). The average score obtained for our story $(M=80)$ indicated that the text was easily readable for the different age groups under study. In addition, a structural analysis of the text based on the grammar of Mandler and Johnson (1977; Johnson \& Mandler, 1980) revealed that the story could be considered simple and well-structured according to the criteria of these authors.

However, there were a few exceptions to this rule. Occasionally, sentences were shortened; that is, important information was omitted that had to be inferred by the reader. Moreover, several contradictions were built into the text that could only be detected by careful monitoring. For example, the hero was first described as a fast soccer player, but later referred to as very slow and sluggish. Though prior knowledge about soccer was important in order to draw correct inferences, it was not always necessary to detect the contradictions in the text.

The story was taped and presented twice to the subjects. While listening to the story, they had an opportunity to read a written version simultaneously. Children were told that it was most important to listen to the story carefully, but that the written version of the text could serve as additional support. About $15 \mathrm{~min}$ later, subjects were given a 10-item questionnaire that tapped memory for text details, detection of contradictions in the text, and the ability to draw correct inferences. Each item on the questionnaire was given a score of 1 to 0 ; a maximum score of 4 was possible for the memory variable, and a maximum score of 3 was possible for each of the text comprehension variables.

\section{Results}

Previous analyses had yielded significant effects of grade and the knowledge base on these three dependent variables: Older children and soccer experts remembered more text details, drew more correct inferences, and detected more contradictions in the text (Weinert et al., 1984). No significant interactions were found in these analyses. The major question of interest in this secondary analysis of the data was whether the subdivision of experts and novices into high- and lowaptitude children described above would lead to a different pattern of results. Preliminary analyses revealed that there were no significant differences in the knowledge base of highversus low-aptitude soccer experts, regardless of age. On the average, experts answered about 10 out of 13 questions on the soccer knowledge questionnaire correctly. Performance ranged from a mean of 9.8 (third graders) to 10.6 (seventh graders). Not surprisingly, novices' performances were considerably lower and ranged from an average of 5.3 points (third 
graders) to 6.1 points (seventh graders). Differences among novice groups were not significant.

Table $I$ contains the means and standard deviations for all three dependent variables as a function of aptitude, grade, and expertise. These data were analyzed in three $2 \times 3 \times 2$ (Aptitude $\times$ Grade $\times$ Expertise) factorial analyses of variance (ANOVAs) with memory for text details, correct inferences, and detection of contradictions as dependent variables.

With regard to memory for text details, there was no effect of aptitude, and no significant interactions were found. Significant main effects were found for grade, $F(2,564)=8.83$, $M S_{\mathrm{e}}=0.63, p<.01$, and expertise, $F(1,564)=13.61, M S_{\mathrm{e}}=$ $0.63, p<.01$. Post hoc comparisons (Student-Newman-Keuls tests) revealed that on the average, fifth and seventh graders remembered more than third graders but did not differ from each other. Moreover, it was found that the two expert groups did not differ from each other but were better than the two novice groups, which showed comparable memory performance.

With regard to the correct inferences variable, there were again no significant effects of aptitude, and no significant interactions. Significant main effects were found for grade, $F(2,564)=14.25, M S_{\mathrm{e}}=0.98, p<.01$, and expertise, $F(1$, 564) $=94.69, M S_{e}=0.83, p<.01$. Subsequent StudentNewman-Keuls tests revealed that seventh graders drew more correct inferences than fifth graders, who in turn scored higher than third graders. The two expert groups did not differ from

Table 1

Means and Standard Deviations for the Three Dependent Variables of Experiment 1 as a Function of Grade, Expertise, and Aptitude

\begin{tabular}{|c|c|c|c|c|c|c|}
\hline \multirow[b]{3}{*}{ Group } & \multicolumn{6}{|c|}{ Variable } \\
\hline & \multicolumn{2}{|c|}{$\begin{array}{l}\text { Text details } \\
\text { (range: } 0-4 \text { ) }\end{array}$} & \multicolumn{2}{|c|}{$\begin{array}{l}\text { Inferences } \\
\text { (range: } 0-3 \text { ) }\end{array}$} & \multicolumn{2}{|c|}{$\begin{array}{l}\text { Contradictions } \\
\text { (range: } 0-3 \text { ) }\end{array}$} \\
\hline & $M$ & $S D$ & $M$ & $S D$ & $M$ & $\overline{S D}$ \\
\hline
\end{tabular}

Grade 3

\begin{tabular}{ccccccc}
$\begin{array}{c}\text { Experts } \\
\text { High aptitude }\end{array}$ & 2.32 & 0.72 & 1.71 & 0.95 & 0.22 & 0.44 \\
Low aptitude & 2.38 & 0.67 & 1.89, & 1.26 & 0.29 & 0.46 \\
Novices & & & & & & \\
High aptitude & 2.02 & 0.77 & 0.60 & 0.63 & 0.07 & 0.26 \\
Low aptitude & 2.01 & 0.75 & 0.83 & 0.60 & 0.07 & 0.26 \\
\hline
\end{tabular}

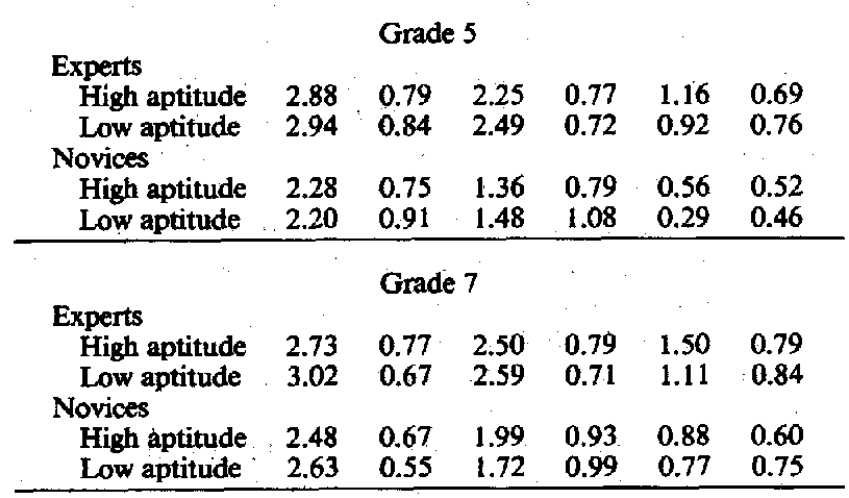

each other but were significantly better than the two novice groups, who showed equivalent performance.

In the ANOVA on detection of contradictions, significant effects were found for grade, $F(2,564)=48.49, M S_{\mathrm{e}}=0.48$, $p<.01$, and expertise, $F(1,564)=28.27, M S_{e}=0.54, p<$ .01. Further, the Aptitude $\times$ Grade interaction was significant, $F(2,564)=3.17, p<.05$. Post hoc analyses revealed that seventh graders detected more contradictions than fifth graders, who in turn were better than third graders. Again, the two expert groups did not differ from each other but were better than the two novice groups, who showed comparable performance. This finding, however, was qualified by the Aptitude $x$ Grade interaction: Whereas the high-aptitude children outperformed the low-aptitude children in seventh grade, aptitude did not make a difference in third and fifth graders.

These findings indicate that performance on the three dependent variables was generally dependent on the children's knowledge base, at any age. That is, in all age groups, soccer experts recalled more text details, drew more correct inferences, and on the average detected more contradictions in the text than did soccer novices. Interestingly, the distinction between soccer experts and novices of different aptitude levels did not change this general pattern of findings. For all three dependent measures, the low-aptitude experts scored significantly higher than the high-aptitude novices. The fact that high- and low-aptitude experts performed almost equally on all three dependent variables is in accord with the assumption that low-aptitude subjects are able to process information effectively in a domain with which they are familiar.

It should be noted, however, that the empirical evidence of Experiment 1 was restricted in that the dependent variables measuring text recall and comprehension consisted of only a few items. For example, comparing memory for a few text details in groups of high- and low-aptitude children does not provide any information about possible quantitative and qualitative differences in high- and low-aptitude children's text processing. Analyses of free recall protocols seem much better suited to explore this issue. Similarly, the measures of text comprehension (i.e., inferences, detection of contradictions) used in Experiment 1 were not comprehensive enough to allow for more general conclusions. For instance, it appears that individual differences in general abilities are correlated with individual differences in declarative as well as procedural metacognitive knowledge, which in turn tend to affect the quality of text processing (see Körkel, 1987; Schneider, 1985). Accordingly, measures of procedural and declarative metacognitive knowledge should also be included to evaluate the relative impact of expertise and aptitude on text comprehension and recall. Experiment 2 (Körkel, 1987) seemed better suited to serve these purposes because several indicators of metacognitive knowledge and memory for test were available in this study.

\section{Experiment 2}

\section{Method}

Subjects. The subjects were 185 middle-class children (64 third graders, 67 fifth graders, 54 seventh graders). Children were selected 
from two public schools located near Heidelberg, West Germany. An equal number of boys and girls were included at each age level.

Measures and procedure. Several variables assessed in Experiment I were also available in Experiment 2. For example, an identical measure of verbal intelligence, the same questionnaire assessing knowledge about soccer, and the same story about a soccer game were used in both studies. As a consequence, the classification of soccer experts and novices with different aptitude levels in Experiment 2 followed the principles of classification reported for Experiment 1.

As already noted, the major advantage of Experiment 2 concerned the selection of dependent measures. Three different memory performance variables were assessed: First, subjects freely recalled the soccer story. The instruction was that the children should do their best to recall the story as accurately and comprehensively as possible. The recall protocols were analyzed according to the procedure developed by Mandler and Johnson (1977), that is, in terms of "semantic" or idea units. At maximum, 36 different idea units could be reproduced.

A cloze test was used as a second measure of (supported) recall. All subjects were presented with a written version of the story that included 20 blanks, and were asked to fill the gaps as accurately as possible. One point was given for each correct completion of the text (maximum score of 20).

Finally, a recognition test was given. The whole test consisted of 24 sentences. In addition to 11 "old," that is, original sentences, 13 "new," distractor sentences were included. Precautions were taken to ensure that the distractor sentences referred to the course of action described in the soccer story, and that they were difficult to identify, that is, that they were similar to old sentences not included in the recognition test. One point was given for each correct identification of an original sentence and for each correct rejection of a distractor sentence. (The maximum possible score was 24.)

In addition to the three performance measures, several indicators of strategic operations and metacognitive processes were available in this study. These indicators included subjects' importance ratings of the text, their performance prediction for the free recall task, their feeling-of-knowing judgments when completing the cloze test, and their declarative metacognitive knowledge about text recall.

The importance rating procedure is a very popular tool in the area of text memory and comprehension (see Brown, Bransford, Ferrara, \& Campione, 1983, for a review). The version used in this study required the children to select and underline those 10 sentences in the soccer text that they considered the most important and necessary for an efficient reproduction of the text. Children's importance ratings were then compared with an "ideal" importance rating of the text based on the judgments of $\mathbf{2 0}$ adult soccer experts (students and faculty members of different departments at the University of Heidelberg). One point was given when a sentence judged as important corresponded with a sentence selected as important by the adult experts (maximum score of 10 ).

Immediately after the importance rating procedure, subjects were asked to predict the number of sentences they could freely recall if asked to do so. Prediction accuracy was assessed by relating performance prediction and actual performance in the free recall task. More precisely, it was defined as the absolute value of the difference between the recall estimate and actual recall, divided by recall. According to this formula, smaller scores correspond with better prediction accuracy.

With regard to the feeling-of-knowing judgments, the relevant information was taken from the cloze test. When completing the blanks in the cloze test, subjects were asked to indicate whether the completion of the text was correct or incorrect in their opinion. Correct evaluations, that is, hits (i.e., both completion and evaluation correct) and correct rejections (i.e., completion incorrect and evaluation correct) were summed, yielding a maximum score of 20 .

Finally, children's declarative metacognitive knowledge (metamemory) about text processing and recall was assessed by using a 17 item questionnaire modeled after the interviews developed by Kreutzer, Leonard, and Flavell (1975) and Myers and Paris (1978). One point was given for each item, thus yielding a maximum score of 17 .

\section{Results}

Preliminary analyses revealed that there were no significant expert/novice differences for two measures, namely the recognition test and the questionnaire assessing declarative metacognitive knowledge. Not surprisingly, subdividing experts and novices according to aptitude level did not change the pattern of results. As a consequence, the findings for those two measures will not be discussed in detail here.

Table 2 contains the means and standard deviations for the remaining two memory variables as a function of aptitude, grade, and expertise. These data were analyzed in two $2 \times 3$ $\times 2$ (Aptitude $\times$ Grade $\times$ Expertise) factorial ANOVAs with free recall and supported recall (cloze test) as dependent variables.

With regard to free recall, there was no effect of aptitude, and no significant interactions. Significant main effects were found for grade, $F(2,173)=18.28, M S_{\mathrm{e}}=20.51, p<.01$, and expertise, $F(1,173)=103.18, M S_{e}=14.20, p<.01$. Subsequent Student-Newman-Keuls tests revealed that sev-

Table 2

Means and Standard Deviations for the Text Recall Variables of Experiment 2 as a Function of Grade, Expertise, and Aptitude

\begin{tabular}{|c|c|c|c|c|}
\hline \multirow[b]{2}{*}{ Group } & \multicolumn{2}{|c|}{$\begin{array}{l}\text { Free recall } \\
\text { (range: } 4-25 \text { ) }\end{array}$} & \multicolumn{2}{|c|}{$\begin{array}{l}\text { Supported } \\
\text { recall } \\
\text { (range: } 5-20 \text { ) }\end{array}$} \\
\hline & $M$ & $S D$ & $M$ & $S D$ \\
\hline & \multicolumn{2}{|c|}{ Grade 3} & & \\
\hline \multicolumn{5}{|l|}{ Experts } \\
\hline High aptitude & 13.94 & 3.49 & 17.22 & 1.69 \\
\hline Low aptitude & 13.60 & 3.37 & 18.40 & 1.07 \\
\hline \multicolumn{5}{|l|}{ Novices } \\
\hline High aptitude & 9.37 & 3.41 & 14.91 & 2.28 \\
\hline Low aptitude & 9.08 & 3.20 & 15.08 & 3.50 \\
\hline \multicolumn{5}{|c|}{ Grade 5} \\
\hline Experts & & & & \\
\hline High aptitude & 16.38 & 2.35 & 16.90 & 1.93 \\
\hline Low aptitude & 17.48 & 2.71 & 17.33 & 1.15 \\
\hline \multicolumn{5}{|l|}{ Novices } \\
\hline High aptitude & 10.93 & 3.44 & 14.61 & 1.99 \\
\hline \multirow[t]{2}{*}{ Low aptitude } & 10.42 & 3.30 & 14.53 & 2.22 \\
\hline & \multicolumn{2}{|c|}{ Grade 7} & & \\
\hline \multicolumn{5}{|l|}{ Experts } \\
\hline High aptitude & 19.00 & 3.46 & 17.60 & 1.27 \\
\hline Low aptitude & 19.80 & 3.36 & 17.10 & 1.37 \\
\hline \multicolumn{5}{|l|}{ Novices } \\
\hline High aptitude & 13.09 & 5.14 & 15.81 & 2.52 \\
\hline Low aptitude & 13.54 & 4.17 & 15.46 & 2.75 \\
\hline
\end{tabular}


enth graders recalled more than fifth graders, who in turn were better than third graders. The two expert groups did not differ from each other but were significantly better than the two novice groups, who showed equivalent performance.

The findings for supported recall were different in that no main effect for grade was found. There was no effect of aptitude, and no significant interactions. The main effect of expertise proved significant, $F(1,173)=40.92, M S_{c}=3.90$, $p<.01$. Again, the two expert groups did not differ from each other but were better than the two novice groups, who showed comparable performance.

Taken together, the findings for the two memory performance variables parallel those obtained for the memory performance variable in Experiment 1. There were pronounced differences between experts and novices, and the distinction between different levels of aptitude did not change this general pattern of results. The high- and low-aptitude experts performed almost equally on the two dependent variables, and there were also no differences in high- and low-aptitude novices' memory performances.

Although these findings seem to indicate that children with different aptitude levels can process new information in a familiar domain equally well, a more conclusive answer to this question can be obtained by directly analyzing the textrelated strategies and metacognitive processes (i.e., memory monitoring) children used while memorizing and comprehending the text information. The three variables to be considered in this context are the quality of subjects' importance ratings, their feeling-of-knowing judgments concerning the appropriateness of their text completion on the cloze test, and their estimates or predictions of free recall.

Table 3 contains the means and standard deviations for these three variables as a function of grade, expertise, and aptitude. These data were analyzed in three $2 \times 3 \times 2$ (Aptitude $\times$ Grade $\times$ Expertise) factorial ANOvas, with importance rating, feeling of knowing, and prediction accuracy as the dependent variables.

With regard to importance rating, the main effect of aptitude was nonsignificant. Significant effects were found for grade, $F(2,173)=3.97, M S_{\mathrm{c}}=2.35, p<.05$, and expertise, $F(1,173)=49.87, M S_{\mathrm{e}}=1.87, p<.01$. Seventh graders selected more important sentences than fifth graders, who in turn were superior to third graders. The pattern of results for expertise resembled those found for the memory performance variables: The two expert groups did not differ from each other, but were significantly better than the two novice groups, who showed equivalent performance.

The latter finding was also true for the two memory monitoring variables (i.e., feeling of knowing and prediction accuracy). The $F \mathrm{~s}(1,173)$ concerning the effects of the expertise variable for the feeling of knowing and prediction accuracy variables were 22.02 and 27.68 , respectively (all $p s<.01$ ). There was a significant grade effect for feeling of knowing. $F(2,173)=3.56, M S_{e}=4.93, p<.05$. Interestingly, no grade effect was found for the prediction accuracy variable. Again, the main effect of aptitude and all interactions were nonsignificant.

Before we can accept the conclusion that individual differences in general aptitude do not have an impact on text
Table 3

Means and Standard Deviations for the Strategy Use and Memory Monitoring Variables of Experiment 2 as a Function of Grade, Expertise, and Aptitude

\begin{tabular}{|c|c|c|c|c|c|c|}
\hline \multirow[b]{3}{*}{ Group } & \multicolumn{6}{|c|}{ Variable } \\
\hline & \multicolumn{2}{|c|}{$\begin{array}{l}\text { Importance } \\
\text { rating } \\
\text { (range: 0-9) }\end{array}$} & \multicolumn{2}{|c|}{$\begin{array}{c}\text { Feeling of } \\
\text { knowing } \\
\text { (range: 8-20) }\end{array}$} & \multicolumn{2}{|c|}{$\begin{array}{c}\text { Performance } \\
\text { prediction } \\
\text { (range: } 0- \\
\text { 1.2) }\end{array}$} \\
\hline & $M$ & $S D$ & $M$ & $S D$ & $M$ & $S D$ \\
\hline \multicolumn{7}{|c|}{ Grade 3} \\
\hline \multicolumn{7}{|l|}{ Experts } \\
\hline High aptitude & 4.33 & 1.83 & 16.05 & 3.28 & 0.21 & 0.19 \\
\hline Low aptitude & 4.50 & 1.83 & 16.80 & 2.40 & 0.23 & 0.11 \\
\hline \multicolumn{7}{|l|}{ Novices } \\
\hline High aptitude & 2.98 & 1.70 & 12.70 & 3.44 & 0.50 & 0.55 \\
\hline Low aptitude & 2.88 & 1.03 & 13.00 & 3.71 & 0.46 & 0.22 \\
\hline \multicolumn{7}{|c|}{ Grade 5} \\
\hline Experts & & & & & & \\
\hline High aptitude & 5.20 & 1.46 & 16.03 & 1.72 & 0.30 & 0.17 \\
\hline Low aptitude & 4.83 & 1.80 & 16.66 & 1.46 & 0.24 & 0.25 \\
\hline \multicolumn{7}{|l|}{ Novices } \\
\hline High aptitude & 3.67 & 1.18 & 14.67 & 2.07 & 0.59 & 0.17 \\
\hline Low aptitude & 3.67 & 1.01 & 14.62 & 2.54 & 0.56 & 0.17 \\
\hline & & Grade & & & & \\
\hline \multicolumn{7}{|l|}{ Experts } \\
\hline High aptitude & 5.80 & 1.32 & 16.20 & 1.64 & 0.14 & 0.17 \\
\hline Low aptitude & 5.90 & 1.28 & 16.00 & 2.05 & 0.23 & 0.15 \\
\hline \multicolumn{7}{|l|}{ Novices } \\
\hline High aptitude & 4.07 & 1.53 & 13.36 & 3.00 & 0.47 & 0.22 \\
\hline Low aptitude & 3.92 & 1.38 & 14.09 & 1.60 & 0.45 & 0.35 \\
\hline
\end{tabular}

comprehension and recall in an area with which subjects are particularly familiar, we must address one theoretically important objection to the way we analyzed the data. That is, our decision to conflate the continuous knowledge and aptitude variables into dichotomous variables implied that a substantial amount of inherent variance was ignored. As a consequence, the probability of finding an effect when one existed was reduced. To test the assumption that our failure to find significant effects of aptitude was due to this methodological problem, we conducted all ANOVAS of Experiment 2 again within a regression model, using the continuous knowledge and intelligence variables as predictor variables. In short, the various multiple regression analyses generally replicated the results reported above. With the exception of the importance rating measure in third grade, where general aptitude accounted for about $10 \%$ of the explained variance, its impact on the dependent measures was consistently low and insignificant. Typically, general aptitude explained between $1 \%$ and $3 \%$ of the variance in the dependent measures. On the other hand, domain-specific knowledge significantly predicted text recall and comprehension, regardless of the dependent variable and age group under consideration. Knowledge usually accounted for more than $25 \%$ of the variance in the dependent variables, reaching a maximum of $45 \%$ for free recall in seventh graders. 
In sum, then, the findings obtained for the dependent variables used in Experiment 2 support the assumption that individual differences in general abilities as assessed in psychometric intelligence tests do not prove important in distinguishing expert and novice performance.

\section{General Discussion}

The two studies summarized in this article assessed the respective roles of domain-specific knowledge and general aptitudes in influencing various aspects of text comprehension and recall. In Experiment 1, soccer experts and novices were compared on their ability to memorize text details, to draw inferences, and to detect contradictions in the text. Not surprisingly, experts outperformed novices on all three outcome measures. More interestingly, the distinction between soccer experts and novices of different aptitude levels did not change this pattern of findings. That is, high- and low-aptitude experts did not differ from each other.

This somewhat unexpected finding was validated by the results of Experiment 2. Hence, it was shown that domainspecific knowledge affected (unassisted and supported) text recall, whereas recognition performance was comparable for experts and novices. These results suggest an interaction between knowledge level and form of test: The soccer expert groups performed well regardless of form of test, whereas the novice groups did better as more prompts were provided for memory. As in Experiment 1, groups of high- and lowaptitude experts did not differ from each other but were clearly superior to the two novice groups. A similar pattern of results was found for the strategy and memory monitoring variables assessed in Experiment 2, thus demonstrating that experts differing in general aptitude were comparable in their strategic processes and memory monitoring skills.

Interestingly, declarative metacognitive knowledge did not differ for the four experimental groups, and its impact on text recall and comprehension was negligible compared with that of the two memory monitoring variables (i.e., feeling of knowing and prediction accuracy). This finding is in line with several recent studies showing that procedural metacognitive knowledge seems a better predictor of text recall, as compared to declarative metacognitive knowledge (see Schneider, 1985, for a review).

By and large, then, the findings of the two studies support the conclusion that children's prior knowledge about text contents is a much more powerful predictor of their text comprehension and recall than their general intellectual ability. The results, thus, confirm the findings of Marr and Gormley (1982) that subjects' prior knowledge and not their general comprehension ability was a crucial factor in explaining performance. It appears, then, that rich domain-specific knowledge can compensate for low overall aptitude on domain-related cognitive tasks.

However, we would still hesitate to generalize these findings. It should be noted that our soccer story was well structured in most parts and easily readable even for third graders. The discrepancy between our results and those obtained by Bransford et al. (1981) could be at least partly due to the fact that their robot story was more difficult to understand and required the ability to draw more complex inferences than was necessary for the children in our studies.

A second reason for the discrepancy between the results of our study and those reported by Bransford et al. (1981) could be the differing levels of expertise observed in the two studies. Though our soccer experts had a pronounced knowledge of soccer rules and important soccer events, the amount of knowledge about robots and their functioning was probably comparably modest even in Bransford et al.'s good learner subjects. It seems, then, that the relative impact of knowledge on text recall and comprehension may vary as a function of task difficulty and the richness of domain-specific knowledge: The more difficult the task demands and the less pronounced the available task-specific knowledge, the more important are strategic processes and general comprehension abilities.

It should be noted, however, that two recently published studies on expertise in a different domain (baseball) provide additional confirmation for the validity of our findings (see Recht \& Leslie, 1988; Walker, 1987). Walker (1987; Experiment 2) compared high- and low-aptitude adults who were either baseball experts or novices. When presented with a baseball text passage, low-aptitude/high-knowledge subjects recalled more information than high-aptitude/low-knowledge subjects. In addition, the two expert groups differing with regard to general aptitude recalled similar amounts of important information and made equivalent numbers of goal-relevant inferences. Recht and Leslie investigated how domainspecific knowledge influences text recall and comprehension of high-knowledge versus low-knowledge seventh- and eighth grade children differing in reading ability. Children had to read a baseball text passage and then reenact the action described in the text nonverbally, retell the story, summarize the text, and sort sentences chosen randomly from the passage on the basis of importance of ideas to the text. On all dependent measures, children with greater knowledge of baseball recalled more than did children with less knowledge. There was no main effect of reading ability, and no significant interaction between reading ability and domain-specific knowledge. As Recht and Leslie emphasized, students with high reading ability but low knowledge of baseball were no more capable of recall or summarization than were students with low reading ability and low knowledge of baseball.

Obviously, the findings presented in the studies by Recht and Leslie (1988) and Walker (1987), as well as those obtained in our study, have direct instructional implications. An impressive result of our study was that even third-grade soccer experts were able to judge adequately the importance of specific text units for later recall, a competence usually not emerging before fifth or sixth grade (see Brown et al., 1983; Schneider, 1985, for reviews). In other words, most lowaptitude soccer experts were well able to show competencies related to academic success in school when they were highly familiar with the contents and also extremely interested and motivated to work on the task. In light of the importance of domain-specific knowledge, strategy instruction and the knowledge base should be considered equally in the design of instruction. As recommended by Walker, one way to teach general cognitive abilities such as organizing, inferencing, and 
comprehension monitoring is in the context of specific knowledge domains. It seems important first to identify low-aptitude learners' preexisting strengths in addition to diagnosing their processing weaknesses, and then to teach these learners to exploit their capabilities in other domains and other task situations.

\section{References}

Amstad, T. (1978) Wie verständlich sind unsere Zeitungen? [How understandable are our newspapers?]. Unpublished doctoral dissertation. University of Zürich.

Bjorklund, D. F. (1985). The role of conceptual knowledge in the development of organization in children's memory. In C. J. Brainerd \& M. Pressley (Eds.), Basic processes in memory development (pp. 103-142). New York: Springer-Verlag.

Bransford, J. D., Stein, B. S., Shelton, T. S., \& Owings, R. A. (1981). Cognition and adaptation: The importance of learning to learn. In J. H. Harvey (Ed.), Cognition, social behavior, and the environment (pp. 93-1 10). Hillsdale, NJ: Erlbaum.

Brown, A. L., Bransford, J. D., Ferrara, R. A., \& Campione, J. C. (1983). Learning, remembering, and understanding. In J. H. Flavell \& E. M. Markman (Eds.), Handbook of child psychology: Vol. 3: Cognitive development (pp. 77-166). New York, NY: Wiley.

Chase, W. G., \& Simon, H. A. (1973). Perception in chess. Cognitive Psychology, 4, 55-81.

Chi, M. T. H. (1978). Knowledge structures and memory development. In R. S. Siegler (Ed.), Children's thinking: What develops? (pp. 73-96). Hillsdale, NJ: Erlbaum.

Chi, M. T. H., \& Ceci, S. J. (1987). Content knowledge: Its role, representation, and restructuring in memory development. In $\mathrm{H}$. W. Reese (Ed.), Advances in child development and behavior (Vol. 20, pp. 91-142). Orlando, FL: Academic Press.

Chi, M. T. H., Glaser, R., \& Rees, E. (1982). Expertise in problem solving. In R. J. Sternberg (Ed.), Advances in the psychology of human intelligence (Vol. 1, pp. 7-75). Hillsdale, NJ: Erlbaum.

Chiesi, H. L., Spilich, G. J., \& Voss, J. F. (1979). Acquisition of domain-related information in relation to high and low domain knowledge. Journal of Verbal Learning and Verbal Behavior, 18 , 257-274.

Gagné, E. (1985). The cognitive psichology of school learning. Boston: Little, Brown.

Garcia, J. (1981). The logic and limits of mental ability testing. American Psychologist, 36, 1172-1180.

Heller, M. S., Gädicke, A. K., \& Weinläder, H. (1985). Kognitiver Fähiqkeitstest für 4. bis 13. Klassen (KFT 4-13) [Cognitive ability test for grades 4 to 13], (2nd ed.), Weinheim, Federal Republic of Germany: Beltz.

Johnson, N. S., \& Mandler, J. M. (1980). A tale of two structures: Underlying surface forms in stories. Poetics, 9, 51-86.

Körkel, J. (1987). Die Entwicklung von Gedächtnis- und Metagedāchtnisleistungen in Abhängigkeit von bereichsspezifischen Vorkenntnissen [The development of memory and metamemory as a func- tion of domain-specific knowledge]. Frankfurt/Main, Federal Republic of Germany: Lang.

Kreutzer, M. A., Leonard, C., \& Flavell, J. H. (1975). An interview study of children's knowledge about memory. Monographs of the Society for Research in Child Development, 40, Serial No. 159.

Mandler, J. M., \& Johnson, N. S. (1977). Remembrance of things parsed: Story structure and recall. Cognitive Psychology, 9, $111-$ 151.

Marr, M. B., \& Gormley, K. (1982). Children's recall of familiar and unfamiliar text. Reading Research Quarterly, 18, 89-104.

Myers, M., \& Paris, S. G. (1978). Children's metacognitive knowledge about reading. Journal of Educational Psychology, 70, 680-690.

Ornstein, P. A., \& Naus, M. J. (1985). Effects of the knowledge base on children's memory strategies. In H. W. Reese (Ed), Advances in child development and behavior (Vol. 19, pp. 138-148). Orlando, FL: Academic Press.

Rabinowitz, M., \& Chi, M. T. H. (1987). An interactive model of strategic processing. In S. J. Ceci (Ed.), Handbook of the cognitive, social, and physiological characteristics of learning disabilities (Vol. 2, pp. 83-102). Hillsdale, NJ: Erlbaum.

Recht, D. R., \& Leslie, L. (1988). Effect of prior knowledge on good and poor readers' memory of text. Journal of Educational Psychology, 80, 16-20.

Schneider, W. (1985). Developmental trends in the metamemorymemory behavior relationship: An integrative review. In D. L. Forrest-Pressley, G. E. MacKinnon, \& T. G. Waller (Eds.), Metacognition, cognition, and human performance (Vol. 1, pp. 57-109). Orlando, FL: Academic Press.

Schneider, W., \& Pressley, M. (1989). Memory development between 2 and 20. New York: Springer-Verlag.

Siegler, R. A., \& Richards, D. D. (1982). The development of intelligence. In R. J. Sternberg (Ed.), Handbook of human intelligence (pp. 897-971). Cambridge, England: Cambridge University Press.

Spilich, G. J., Vesonder, G. T., Chiesi, H. L., \& Voss, J. F. (1979). Text processing of domain-related information for individuals with high and low domain knowledge. Journal of Verbal Learning and Verbal Behavior, 18, 275-290.

Walker, C. H. (1987). Relative importance of domain knowledge and overall aptitude on acquisition of domain-related information. Cognition and Instruction, 4, 25-42.

Weinert, F. E., Knopf, M., Körkel, J., Schneider, W., Vogel, K., \& Wetzel, M. (1984). Die Entwicklung einiger Gedächtnisleistungen bei Kindern und älteren Erwachsenen in Abhängigkeit von kognitiven, metakognitiven und motivationalen Einflussfaktoren [The development of memory performance in children and the elderly as a function of cognitive, metacognitive, and motivational factors]. In K. E. Grossmann \& P. Lütkenhaus (Eds.), Bericht über die 6. Tagung Entwicklungspsychologie [Proceedings of the 6th meeting of German development psychologists], (Vol. 2, pp. 313326). Regensburg, Federal Republic of Germany: UniversitätsDruckerei.

Received September 17, 1987

Revision received January 23, 1989

Accepted January 30, 1989 